\title{
Small Composition-X System of Air Flow \& Solar with Novel SWAY Translate to Enhance the SWAY Quality
}

\author{
K.Boopathy, Aboobacker Nihal, Anwar P Nazar, Sarath T
}

\begin{abstract}
This work mainly focussed on the composition-X system which is a grouping of solar and air flow stamina sway generation techniques. Which is fresh and inexpensive for the forthcoming point of view? In this article a non-conventional stamina composition- $X$ sway organization based on solar cell and air flow, and provides the stamina storage system. DC production of solar stamina conversion system (SECS) and translate DC yield of the air flow stamina conversion system (WECS) is served to the setup chopper which is functioning in closed-loop in-order to preserve constant yield sway in any eco-friendly situation. AIR FLOW comprises of air flow turbines with permanent magnet synchronous gen (PMSGx) and the solar system consists of PV cell The yield of the setup translate is feed to the mutual dc link, which is connected to the six pulsed Dc to AC_xs which convert its solar input to sine wave yield. The practical setup of the proposed model has been implemented and results are analysed in term of sway quality.
\end{abstract}

Keywords: Solar cell, Air flow system, step-up translate, Atmega xx, VSIx, Battery storage.

\section{INTRODUCTION}

The grouping of non-conventional stamina sources, WECS \& PV are used for generating sway called as air flow solar composition-X system. The usage of solar stamina and air flow stamina had been augmented meaningfully due to the quick Progress of sway electronics translate modelling aspect techniques. Stamina is serious to the monetary development and social expansion of every place.

\section{LITERATURE SURVEY}

Original stamina resources essential to be developed to the optimum level to minimize dependence on imported fuels, subject to resolving economic, conservational and community restrictions.[1]. This commanded to a lift in research and development as well as venture in non conventional stamina industry in exploration of ways to chance stamina request and to decrease addiction on fossil fuels with striving but achievable target of $10 \mathrm{TW}$ by 2025 . Air flow and solar stamina are attractive widespread outstanding to sufficiently, handiness and ease of binding for sway generation in any form. Since sunlit days are usually peaceful and robust air

Revised Manuscript Received on December 30, 2019.

Dr.K.Boopathy*, Professor, Dept. of EEE, Aarupadai Veedu Instituite of Technology which is part of Vinayaka Missions Research Foundation, Chennai, India. Email: boopathyk@avit.ac.in

Aboobacker Nihal, Anwar P Nazar, Sarath T, Student, Department of EEE, Aarupadai Veedu Instituite of Technology, Vinayaka Missions Research Foundation, Chennai, India. flows are frequently arisen at overcast days or at moon time [3-4].

So, the composition-X solar/air flow stamina system therefore has developed consistency to carry nonstop sway than either Distinct source [2-3] Conventionally, a considerable stamina storage battery bank is used to deliver the reliable sway and to draw the supreme sway from the solar arrays or the air flow system for both one of them has an erratic nature.[5-7]. However, the battery is not an ecological outgoing invention because of its heavyweights, huge size, tall prices, partial time, and foil the environmental situation

So, it is very mutual to utilize the PV cell or air flow system by relating them to the grid mains directly [4]. Usually, two detached Dc to AC_xs for the solar array and the air flow system are used for the composition-X PV/air flow sway system [5]. A substitute tactic is to practice the Mixed-input Dc to AC _ $\mathrm{x}$ for joining these non-conventional stamina sources in the Dc end instead of the Ac end. It can simplify the composition-X PV/air flow sway system and reduce the costs [5-7]. The main focus of this article is to suggest a new sway Dc to AC _ $\mathrm{x}$ for grid-connected composition-X Solar/air flow sway system [9-11].

\section{DESCRIPTION OF VARIOUS PARAMETERS}

\section{A. PV array}

Alteration of sunny stamina in electrical stamina is founded on a spectacle called sunny effect. When electronics devices resources are showing too sunny, the some of the photons- of sunny ray are absorbed by the electronics devices quartz which causes a significant number of free e- motion in the quartz. This is the elementary motive for creating electricity due to sunny effect. Solar Panel-E cell is the elementary unit of the system where the sunny effect is utilized to harvest electricity from sunny stamina. Si-xm is the most extensively used electronics devices resources for constructing the Solar Panel -E cell. The Si-xm atom has four valence-x e- motion. In hard quartz, each $\mathrm{Si}-\mathrm{xm}$ atom shares each of its four valence e- motion with another nearest $\mathrm{Si}-\mathrm{xm}$ atom hence creating covalent promises between them. In this way, $\mathrm{Si}-\mathrm{xm}$ quartz gets a tetrahedral matrix construction. While sunny ray strikes on any resources some portion of the sunny is reflected, certain share is conveyed through the resources and rest is absorbed by the resources.

The similar thing occurs when sunny cascades on a $\mathrm{Si}$-xm quartz. If the strength of occasion sunny is high enough, 


\section{Small Composition-X System of Air Flow \& Solar with Novel SWAY Translate to Enhance the SWAY Quality}

satisfactory statistics of photons- are absorbed by the quartz and these photons-, in turn, stimulate some of the e- motion of covalent- ties. These excited e- motion then get adequate stamina to migrate from valence gang to inspiration cooperative. As the stamina level of these e- motions is in the motivation joint, they leave from the covalent promise leaving a hole in the word behindhand each removed electron. These are called free e- motion move arbitrarily secret the quartz structure of the Si-xm. These free e- motion and positive atoms have a vital role in creating electricity in Solar Panel -E cell. These e- motion and positive atoms are hence called sunny-generated e- motion and positive atoms separately. These sunny produced e- motion and positive atoms cannot produce electricity in the $\mathrm{Si}$-xm quartz only.

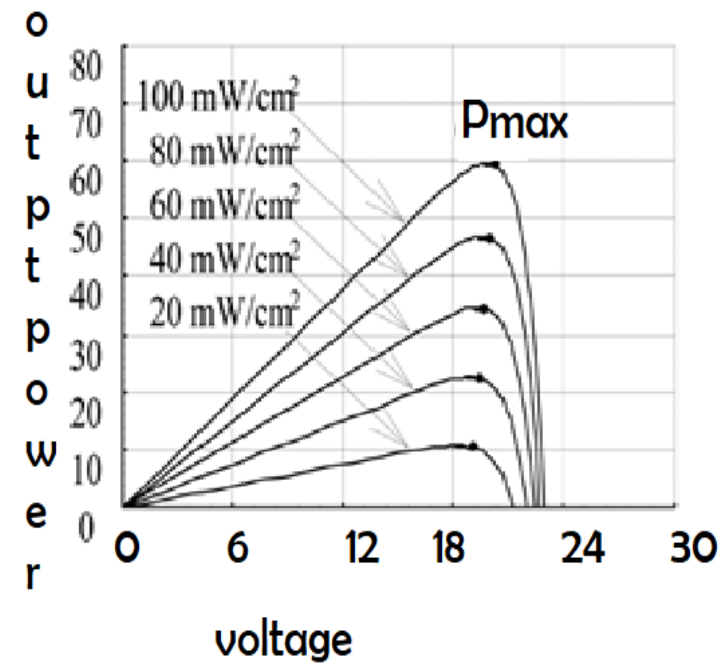

Fig. 1. PV - Sway vs Yield Potential

It can be seen that a supreme sway point exists on each yield sway characteristic curve show in figure 1 . Therefore, to utilize the supreme yield sway from the PV array, an appropriate control algorithm must be adopted.

\section{B. Wind system}

When the air flow strikes the spinning part blades-, bladestwitch spinning. The turbine spinning part is associated to a high-movement gearbox. Gearbox transforms the spinning part movement from low movement to high movement. Innings at a higher movement all elements are show in figure 2 . The produced potential_at yield terminals of the alternator is proportional to both the movement and field flux of the alternator. The movement is governed by air flow sway which is out of control. Hence to uphold consistency of the yield sway from the alternator, excitation must be controlled according to the obtainability of usual air flow sway.

The positioning of the nacelle- or the complete body of the turbine can trail the course of changing air flow route to maximize mechanical stamina gathering from the air flow. The track of the air flow along with its movement is detected by an anemometer- (automatic movement measuring devices) with air flow vanes attached to the back top of the nacelle-. The signal is suckled back to an electronic microprocessor-based regulatory system.

$$
P_{\kappa}=\frac{1}{2} \rho A V_{a}\left(V_{1}^{2}-V_{2}^{2}\right) \ldots \ldots
$$

It can be From equation (2) Air sway

- Sway output is depends on wind quantity and turbine movement both are directly propositional to sway

- Straight relative to the swept area of the turbine edges. If the length of the edge increases, the radius of the brushed area increases consequently, so turbine out -sway growths.

- Wind sway is propositional to cube of wind velocity that means that sway is captivated in to eight times

A core Block diagram of an air flow turbine

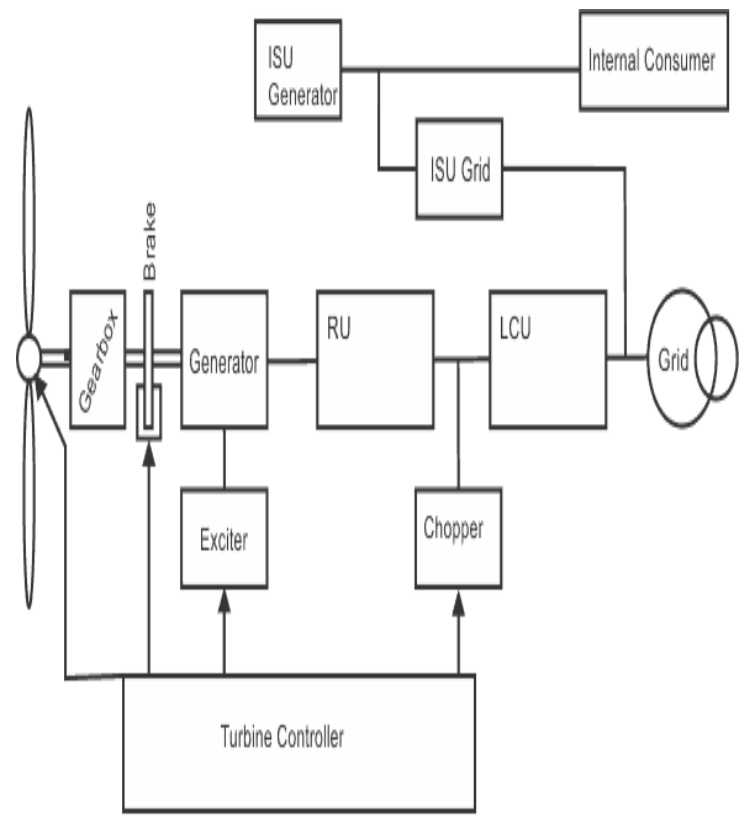

Fig. 2. Block Diagram of WECS

\section{LIFT translate}

When the air DC-DC translators are also recognized as Choppers-x Devices. Here we will have a look at Step up Lift translate which can operate as a DC-DC Step-Down translates or a DC-DC Potential_-Up translate depending upon the triggering sequence.

The source volt source is linked to a compact state scheme. The second button recycled is a PN device. The PN device is connected, in opposite to the route of sway flow from source, to a capacitor and the load and the two are related in parallel as shown in the figure above.

The controlled button is twisted on and off by using Pulse Width Modulation-x (PWiM). PWiM can be time founded or oscillation based. Swaying based variation has drawbacks like a wide range of swaying to realize the desired control of the button which in shot will give the wanted yield potential_. Time based Inflection is mostly used for DiC-DiC-x translators.

It is simple to build and use. The oscillation remains endless in this 
type of PWiM-x variation.

\section{Mixed level Dc to AC_x}

Mixed level cascaded Dc to $\mathrm{AC} \_\mathrm{x}$ has been proposed for such presentations as static var generation show in figure 3 , an interface with non-conventional stamina sources, and for battery-based solicitation. Three-phase cascaded Dc to AC _xs can be connected in normal form.

The Dc to AC _ x could be controlled to either regulate the sway factor of the current drawn from the source or the bus potential_of the electrical system where the Dc to AC _x was connected. V. Peng and Joos AS have also mention in various Dc to $A C$ _ $x$ that a back Dc to $A C{ }_{2} \mathrm{x}$ can be directly connected in series with the electrical system for static VAR compensation. Back back Dc to AC_xs are ideal for connecting non-conventional stamina sources with an $\mathrm{AiC}$ grid, as of the requirement for separate Dic sources, which is the case in solicitation such as $\mathrm{Pv \_}$. modules or fuel cells.

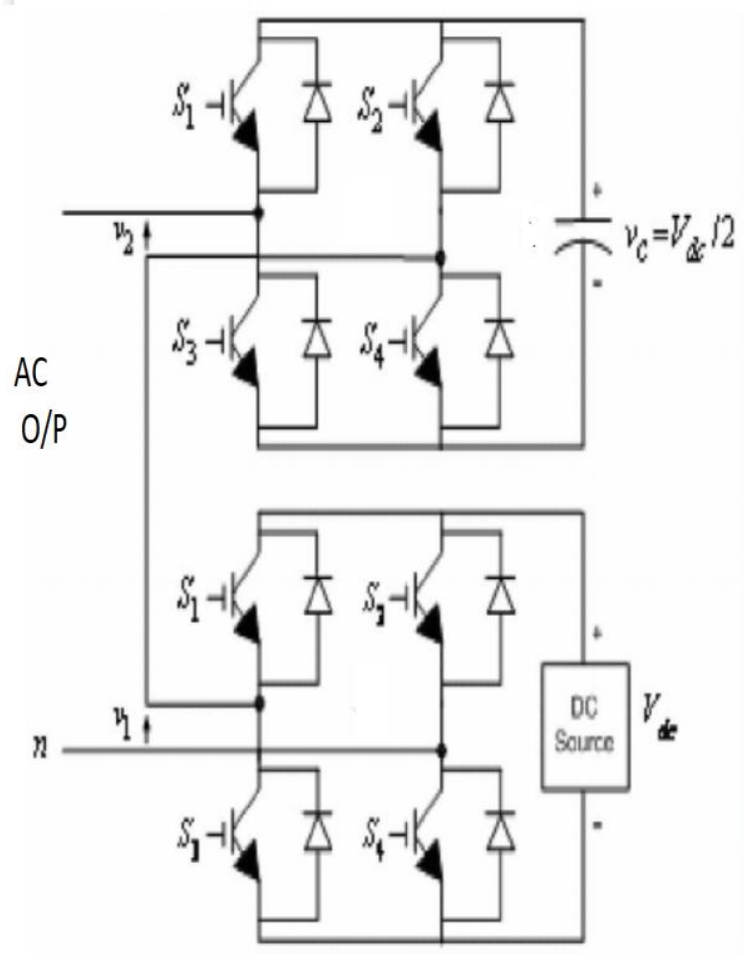

Fig. 3. Mixed level Dc to AC_x with two sources

Figure 3 shows that the combined input potential_sources are changed in to AC by multilevel inverter. Here four button devices are used with flywheel PN device to bring smooth waveform.

Based on the above operation the many number of combinations can be included in the network using supreme sway transfer theorem concepts. Switching devices are main elements in the inverter to get required potential with perfect waveform.

\section{PROPOSED COMPOSITION-X PV/AIR FLOW SYSTEM}

The composition-X structure contains of a set up potential_- Lift translate, a air flow system, and solar arrays. In this system the PV, AIR FLOW, chopper circuit and Mixed
Dc to $\mathrm{AC}$ _x with various storage elements show in figure 4.

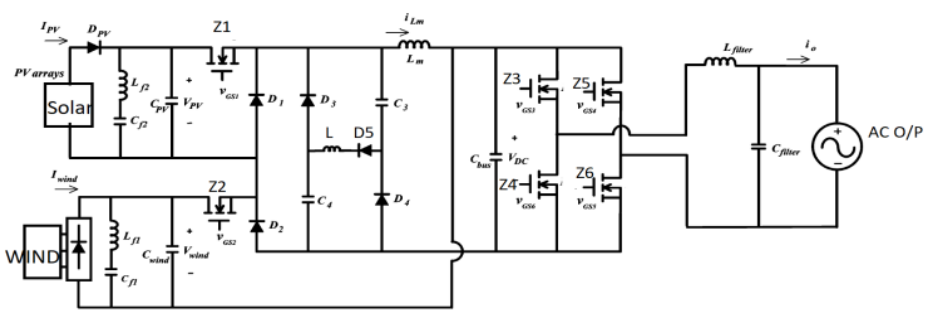

Fig. 4. Composition-X System with Load

The specific lift translators are used to regulator the flow of sway to the consumer. The control line of this common DiC link is connected to a Dc to AC_x. Sway will be produced with the aid of both solar cell \& air flow stamina and will be full to the same bus bar from where sway is complete to the consumer. Sway flow system could be observed as $\mathrm{PV}-\mathrm{DiC} /$ DiC Lift translate-Mutual DiC link. And for air flow stamina, Sway flow can be observed as Air flow stamina-gen set-translate-lift Translate-Mutual DiC Link. Mutual DiC link potential_ is given as an input to the VSI (Dc to AC_x). Lift translate is operating in a open loop to preserve the constant DiC yield potential_. The entire circuit has modeled using arduino technique in hardware implementation to produce yield shown in figure 4 .

Translate specification:

Source volts V DC $=0-20 \mathrm{v}$

Air flow $\mathrm{V} \mathrm{AC}=0-50,50 \mathrm{~Hz}$

DiC bus potential_ V DC- 24-28V

Yield potential_V AC Hz- 90v, $50 \mathrm{~Hz}$

Yield sway $=50 \mathrm{~W}$

Buttoning oscillation- 10 to $20 \mathrm{Khz}$

In the hardware implementation potential_ control device like MOSFET and PN device are preferred to get required potential_. The frequency can be increased by adopting suitable duty cycle.

Duty cycle - Ton / T

Ton - on time of switching device $\mathrm{T}-$ Total

time $($ Ton $+\mathrm{T}$ off $)$

\section{HARDWARE MODEL}

The hardware of a composition system is intended based on the parameters registered in Table II and figure 5 hardware configuration. Then the translate operates at $15 \mathrm{kHz}$ switching rate. Two n-type MOSFET buttons and two Schottky barrier PN devices are used for composition system configuration. The MOSFET switches and PN devices are IRF540_x and 1N5817_x, separately. Controller has been applied using a Texas Instrument digital signal processor (DSiP) (320Fx2812). The output potential_reference is set to $28 \mathrm{~V}$, and input potential_differs from 22 to $24 \mathrm{~V}$. 


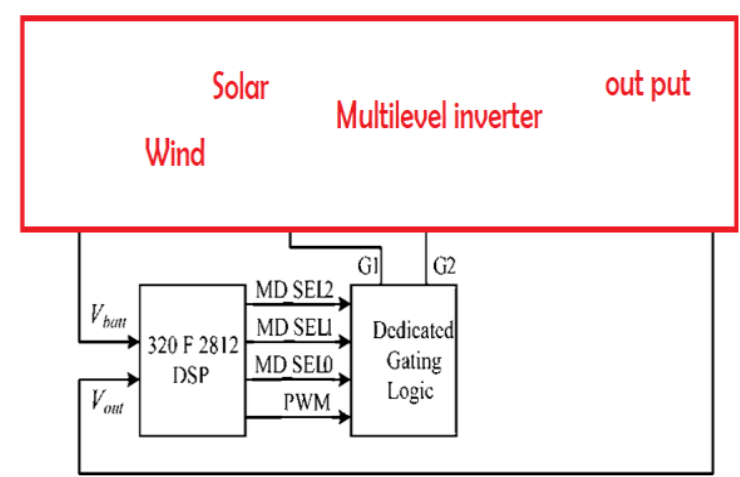

Fig. 5. Hardware Configuration

Table- I: Hardware Specification for actual buck boost translate

\begin{tabular}{|c|c|}
\hline Parameter & Value \\
\hline Digital Signal Processor (DSP) & $320 \mathrm{~F} 2812$ \\
\hline n-type MOSFET & IRF540 \\
\hline Schottky barrier PN device & $1 \mathrm{~N} 5817$ \\
\hline Switching frequency & $100 \mathrm{KHz}$ \\
\hline Output resistance & $30 \Omega$ \\
\hline Output filter capacitance & $400 \mu \mathrm{F}$ \\
\hline Magnetizing inductance & $110 \mu \mathrm{H}$ \\
\hline Input potential_ & $22 \mathrm{~V}-24 \mathrm{~V}$ \\
\hline Output potential_ & $28 \mathrm{~V}$ \\
\hline
\end{tabular}

Two high-side opening drivers are intended for IRFi540. The enthusiastic triggering logic is applied to the translate for correct operation as translate and inverter mode. The functioning modes are dependent on mode collection indications, practical from DSiP.

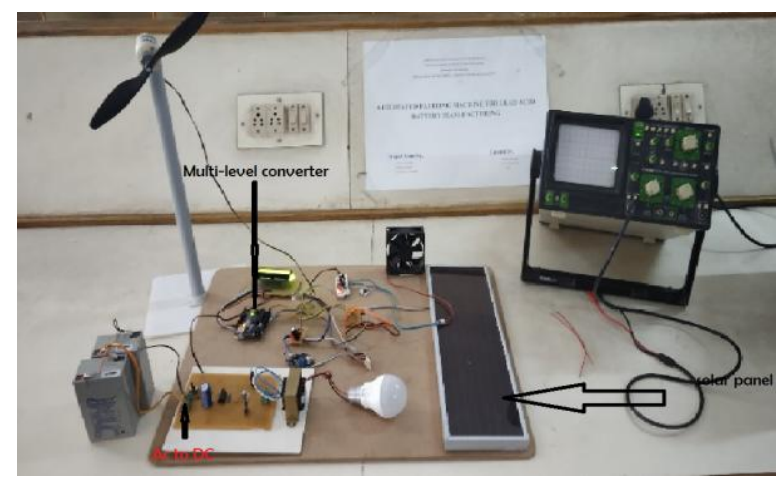

Fig. 6. Composition-X System Model

Figure 6 shows that the hardware set up of proposed work with allinternal components. Solar panel and air flow conversion system with Permanentmagnet synchronous generator and load (100w lamp). The display device is fixedon the left side in the color of yellow and battery for storage of stamina purposeand offline application.

To substantiate the concert of the planned Mixed-input Dc to $\mathrm{AC}$ _ $\mathrm{x}$ for local grid, composition-X solar /air flow sway system shown in figure 6 , a sample model with the conditions. The PV array is moulded by 24 series-connected solar panel pixels with small model of PMSG gen set to produce DC potential_. Each PV array has peak sway of $40 \mathrm{~W}$ and open potential_ of $48 \mathrm{~V}$. The air flow turbine is a 3-phase permanent magnetic generator with esteemed sway of $50 \mathrm{~W}$ at observed air flow movement of $10.5 \mathrm{~m} / \mathrm{s}$.

\section{HARDWARE RESULTS}

\section{A. Input of PV yield (V/I)}

The potential and current waveform of the solar cell array is shown in figure 7. From the curve, it is observed that potential_is $20-22 \mathrm{v}$ and the current is varied from $1 \mathrm{~A}$ to $2 \mathrm{~A}$.

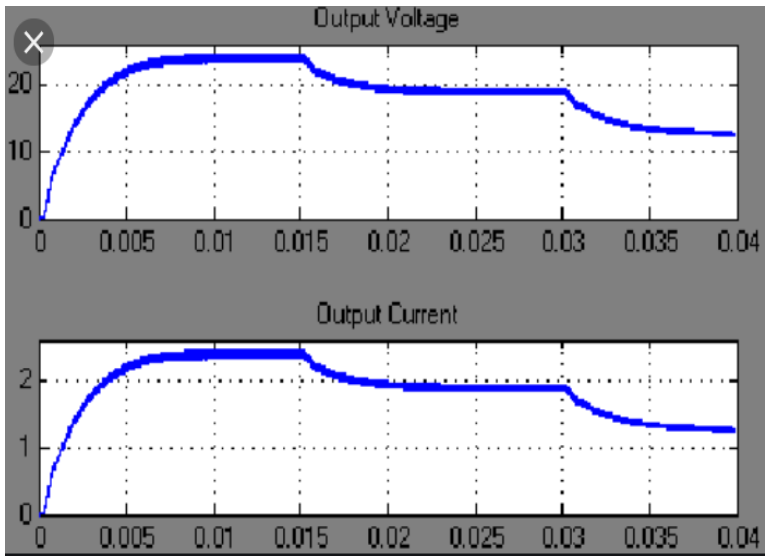

Fig. 7. Yield Potential_Current of PV cell

\section{B. Air flow yield}

In figure 8 shows that the yield potential_of the air flow stamina conversion system for various positions. The potential_ level is $20-21 \mathrm{v}$ in the average condition and air flow movement is assumed between $8-10 \mathrm{~m} / \mathrm{s}$ range.

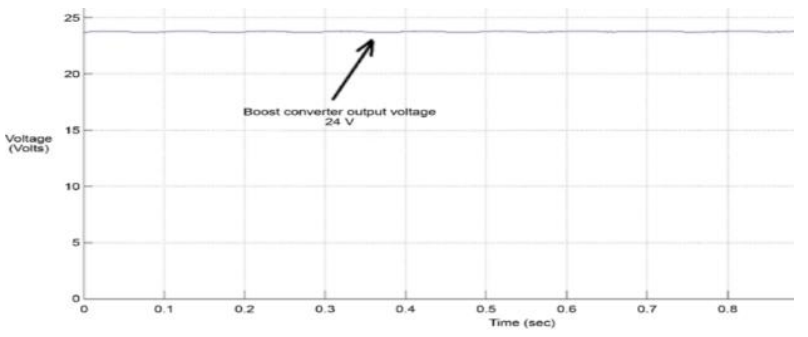

Fig. 8. DC link Yield potential

Figure 8 shows the waveforms of the $\mathrm{DiC}$ bus over-potential safety with less ripple content. This is the potential to be changed to the AC level to meet the load specification.

\section{AC yield}




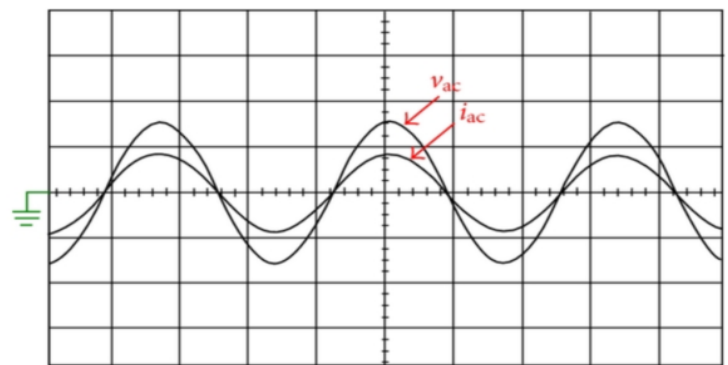

( $V_{\mathrm{ac}}: 100 \mathrm{~V} / \mathrm{div} ; i_{\mathrm{ac}}: 5 \mathrm{~A} / \mathrm{div}$, time: $5 \mathrm{~ms} / \mathrm{div}$ )

\section{Fig. 9. AC load Yield potential_ with current}

Figure 9 shows the yield waveform of the Dc to AC _ $\mathrm{x}$ with load current. Where the dignified sway factor is 0.819 and the THD current is about 7.9\%. The investigational results obviously show that the proposed composition-X PV/air flow sway system can draw sway from the PV array and the air flow turbine independently or concurrently with a joint source future. Also, closely unity sway factor and real low vocal current change can be realized by less no. of buttoning devices.

\section{CONCLUSION}

A In this is work, the Mixed level Dc to AC_x concept is implemented in a composition-X system which is combined stamina sources of air flow and solar module. The potential_ and current waveform of various stages are discussed in terms of sway quality. It proves that the Mixed level Dc to AC _ $\mathrm{x}$ has a good performance compared to the series Dc to AC _ $\mathrm{x}$ model. The sway quality parameter of THD is reduced from $84 \%$ to $75 \%$ with a compact circuit and implemented in a practical aspect. In proposed model has the following merits: sway from the solar array or the air flow turbine can be distributed to any load, a huge range of source volt distinction begun by different positions and air flow movement is suitable.

\section{ACKNOWLEDGMENT}

The author would like to honestly thanks to the organization, Principle and Dr.L. Chitra AVIT- VMRF for the purchase of a swaying quality analyzer kit in the research center

\section{REFERENCES}

1. Boopathy K., and Bhoopathy Bagan K., Presented and published in IEEE Explore a paper title on "A Novel Method of Implementing Real-Time Step up Boost Translate with Improved Transient Response for Low Sway Solicitation" in 2011 IEEE ISIEA International Conference organized by IEEE Symposium on Industrial Electronics \& Solicitation, Ref No:978-1-4577-1416-0/11/PP 155-160, 2011.

2. S. Wakao, R. Ando, H. Minami, F. Shinomiya, A. Suzuki, M. Yahagi, S. Hirota, Y. Ohhashi, and A. Ishii, "Performance analysis of the PV/air flow/wave composition-X sway generation system," in Proc. IEEE World Conf. Photovolt. Stamina Conv., 2003, pp. 2337-2340.

3. J. H. R. Enslin and D. B. Snyman, "Combined low-cost, high-efficient Dc to $\mathrm{AC}_{-} \mathrm{x}$, peak sway tracker and regulator for PV solicitation," IEEE Tran. Sway Electron., vol. 6, no. 1, pp. 73-82, Jan. 1991

4. Boopathy K., Divya Vijay "Mixed-objective Genetic Algorithm based Sliding Mode Control for Assured Crew Re-Entry Vehicle" Springer Nature-Journal of Advanced in Intelligent System, Volume 517, Issue I, February 2017, pp 491-504.
5. Boopathy, Shanthini "Movement Control and Sway factor Correction using Bridgeless Step up Boost Translate for BLDC Device Drive" International Journal of Science, Engineering and Technology Research Volume 4, Issue 4, April 2015,pp 446- 451.

6. Boopathy, K. and Bhoopathy Bagan, K. "Real-Time Step up Boost Translate with Improved Transient Response for battery Sway Solicitation" International Journal of Electrical Engineering. Vol.10, pp. 1-6, 2012

7. Boopathy, K. and Bhoopathy Bagan, K. "Digital Combination of Real Time Step up Boost Translate Using a Soft Technique to Reduce Transient Overshoot," International Journal of Electrical Engineering. Vol.12, pp. 1-6, 2012.

8. R. Cardenas, R. Pena, G. Asher, and J. Cilia, "Sensorless control of induction machines for air flow stamina solicitation," in Proc. IEEE PESC,2002, pp. 265-270..

9. Y.-M. Chen, Y.-C. Liu, and S.-H. Lin, "Double-Input PWM DC/DC translate for high/low potential_ sources," in Proc. IEEE Int. Telecommun. Stamina Conf., 2003, pp. 27-32.

10. Manimaran. V. B, "Design and Implementation of Solar-Wind Combo For Hybrid Energy Application," International Journal of MC Square Scientific Research, vol.5, No.1 Nov 2013.

11. S.Siva, "Automatic Solar Tracker", International Journal of MC Square Scientific Research Vol.8, No.1 Nov 2016

\section{AUTHORS PROFILE}

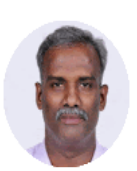

Dr.K.Boopathy profile received the B.E from Madras University (Electrical \& Electronics Engineering) in 1999, M.E in Electronic Engineering from Anna University(MIT campus) in 2003, and $\mathrm{Ph} . \mathrm{D}$ in power electronics from Anna University, Chennai in 2012. Currently he is working as a Professor in Dept. of EEE AVIT-VMRF,OMR Chennai. He has published several National and International Journals and Conferences. His area of interest is Power Electronics and Drives, soft computing technique application to power electronics and electrical machines.. e-mail: boopathyk@avit.ac.in

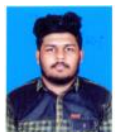

Aboobacker nihal, have been studied in the department of EEE in the academic year 2018-19, AVIT, and presently they are working in various reputed industries.

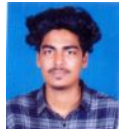

Anwar p nazar, have been studied in the department of EEE in the academic year 2018-19, AVIT, and presently they are working in various reputed industries.

Sarath $\mathbf{T}$ have been studied in the department of EEE in the academic year 2018-19, AVIT, and presently they are working in various reputed industries. 